\title{
Three-dimensional Force and Kinematic Interactions in V1 Skating at High Speeds
}

\author{
THOMAS STÖGGL ${ }^{1,2}$ and HANS-CHRISTER HOLMBERG ${ }^{2,3}$ \\ ${ }^{1}$ Department of Sport Science and Kinesiology, University of Salzburg, Salzburg, AUSTRIA; ${ }^{2}$ Swedish Winter Sports Research \\ Centre, Department of Health Sciences, Mid Sweden University, Östersund, SWEDEN; and ${ }^{3}$ Swedish Olympic Committee, \\ Stockholm, SWEDEN
}

\begin{abstract}
STÖGGL, T., and H.-C. HOLMBERG. Three-dimensional Force and Kinematic Interactions in V1 Skating at High Speeds. Med. Sci. Sports Exerc., Vol. 47, No. 6, pp. 1232-1242, 2015. Purpose: To describe the detailed kinetics and kinematics associated with use of the V1 skating technique at high skiing speeds and to identify factors that predict performance. Methods: Fifteen elite male cross-country skiers performed an incremental roller-skiing speed test $\left(V_{\text {peak }}\right)$ on a treadmill using the V1 skating technique. Pole and plantar forces and wholebody kinematics were monitored at four submaximal speeds. Results: The propulsive force of the "strong side" pole was greater than that of the "weak side" $(P<0.01)$, but no difference was observed for the legs. The poles generated approximately $44 \%$ of the total propulsion, being more effective than the legs in this respect $(\sim 59 \%$ vs $11 \%, P<0.001)$. Faster skiers exhibited more well-synchronized poling, exhibited more symmetric edging by and forces from the legs, and were more effective in transformation of resultant forces into propulsion. Cycle length was not correlated with either $V_{\text {peak }}$ or the impulse of total propulsive forces. Conclusions: The present findings provide novel insights into the coordination, kinetics, and kinematics of the arm and leg motion by elite athletes while V1 skating at high speeds. The faster skiers exhibit more symmetric leg motion on the "strong" and "weak" sides, as well as more synchronized poling. With respect to methods, the pressure insoles and three-dimensional kinematics in combination with the leg push-off model described here can easily be applied to all skating techniques, aiding in the evaluation of skiing techniques and comparison of effectiveness. Key Words: 3D KINEMATICS, FORCE COMPONENTS, KINETICS, PRESSURE DISTRIBUTION INSOLES, PROPULSIVE FORCE
\end{abstract}

$\mathrm{T}$ The skating techniques used in cross-country (XC) skiing have gone through a remarkable evolution since this style first appeared in the early 1980s. The most common techniques used during racing are V1 and V2, and these are performed at various inclines (30). Briefly, V1 skating involves asymmetric poling on every second leg stroke, whereas V2, mainly used on level terrain and moderate uphill inclines, is characterized by single poling on every leg stroke. In particular, the introduction of sprint competitions involving greater skiing speeds in the late 1990s has contributed to the development of new techniques such as V2"double-push" and V1-jump skating (35). Although much pioneering research on the various skating techniques was published before the turn of the present century $(4-7,11,17$, $26,27,29,31,32,38,39)$, few investigations have focused on more modern skating techniques, in particular V1 skating $(2,16,19,21,30,35)$.

Address for correspondence: Assoc. Prof. Mag. Dr. Thomas Stöggl, Department of Sport Science and Kinesiology, Schlossallee 49, 5400 Hallein/Rif, Austria; E-mail: thomas.stoeggl@sbg.ac.at.

Submitted for publication April 2014.

Accepted for publication September 2014.

0195-9131/15/4706-1232/0

MEDICINE \& SCIENCE IN SPORTS \& EXERCISE ${ }_{\circledast}$

Copyright $(C) 2014$ by the American College of Sports Medicine

DOI: 10.1249/MSS.0000000000000510
In most XC skiing competitions, uphill sections account for approximately one third of the course length (10) and half of the skier's racing time (16). The V1 skating technique is commonly used on moderate inclines and is the most common technique for steep uphill skiing. Accordingly, insight into the mechanics associated with this technique is crucial to understanding skating performance during modern XC skiing.

Although several studies have characterized various skating techniques on flat terrain $(6,7,11,12,20,22,37)$, much less is known about moderate-to-steep-uphill terrain $(4,6,7,20,24,25$, $30,35)$. Moreover, most previous uphill investigations involved only kinematic measurements designed to evaluate cycle characteristics, with a primary focus on describing techniques. Millet et al. (20) compared pole forces on different inclines, whereas reports on the kinetics of the leg pushoff during uphill skating are scarce $(26,30,33,35,38)$.

During XC skiing, air drag, gravity, and friction must be overcome by forces generated through the poles and legs. Therefore, in addition to their interest from the perspective of biomechanics, determination of force components and the relative contributions of upper-and-lower-body work to propulsion and the skiers' effectiveness may help coaches and athletes develop more effective techniques. However, there seems to be some discrepancy concerning the relative upper- and lower-body contributions and their relationship to performance during V1 skating. 
Although Wenger et al. (41) examined propulsive forces during V1 and V2 skating, they failed to describe the methodological approach used. Both Babiel and Neumaier (3) and Street and Frederick (39) reported on three-dimensional (3D) forces along the ski but provided no further information relevant to this technique. With respect to the distribution of propulsive forces via the arms versus the legs during V1 skating, Street (38) demonstrated a rather equal distribution, whereas Smith (26) reported that pole forces contributed approximately $66 \%$. In both of these studies, leg forces were observed to be greatest in the vertical and lateral directions, serving primarily to propel lateral motion and support the body against gravity but contributing little to propelling the skier uphill. Furthermore, the single report about mechanical effectiveness during skating published by Smith et al. (30) concluded that the contribution of the upper body was greater with the V2 technique, whereas leg work was more pronounced with V1. However, relationships between the mechanics of these techniques and performance were not explored.

With respect to V1 skating performance, several groups have reported that faster skiers apply longer cycle lengths, with no difference in cycle rate $(4,7,11,31)$. In another study by Smith et al. (32), cycle velocity and cycle rate were related in the case of the women skiers, but not the men, with no correlation between cycle length and cycle velocity for either group. Lee et al. (17) demonstrated that more skilled skiers use longer cycle lengths and higher cycle rates. In addition, some of the available reports on ski and pole angles during V1 skating indicate that faster skiers apply smaller ski angles $(17,31)$, whereas in another case, no such difference was observed (11).

In light of these observations, the present investigation was designed to (a) provide a basic description of the biomechanics of the V1 technique, (b) determine factors that predict performance, and (c) compare force components for the upper and lower body and their relationship to effectiveness at a wide range of high submaximal skiing speeds. Our hypothesis was that better XC skiers demonstrate more effective pole and leg thrusts, along with greater propulsive force impulses per cycle and longer cycle lengths.

\section{METHODS}

Participants. The 15 elite male sprint skiers (age $=26.1 \pm$ $4.7 \mathrm{yr}$, body mass $=75.3 \pm 4.3 \mathrm{~kg}$, body height $=180 \pm 5 \mathrm{~cm}$ [means $\pm \mathrm{SD}]$ ) who volunteered to participate were members of the Swedish, Austrian, and Norwegian national teams, competing at the national $(n=6)$ or international level $(n=9)$. This group included one medalist from the Sprint World Championship, one winner of the overall Sprint World Cup, and three World Cup winners, and moreover, nine of these skiers were ranked among the top 20 in World Cup races. All were fully informed about the nature of the study before providing their written consent to participate, and the protocol was preapproved by the Regional Ethical Review Board in Umeå, Sweden (no. 08-058 M).
General design. While roller skiing during an incremental peak speed test $\left(V_{\text {peak }}\right)$ on a treadmill with the V1 skating technique using the dominant side (six right and nine left), pole and plantar forces and three-dimensional whole-body kinematics (including the poles and roller skis) were analyzed at four submaximal speeds $\left(13,14,15\right.$, and $\left.16 \mathrm{~km} \cdot \mathrm{h}^{-1}\right)$ on a $7^{\circ}$ incline. The slightly modified skating push-off model described by Smith (28) was used to calculate force components on the basis of data provided by an insole system together with the three-dimensional kinematics.

The V1 skating technique. During V1 skating, which is generally considered to be an uphill technique, the right and left sides of the body function asymmetrically and asynchronously. During leg push-off, pole support is used on one side of the body only (referred to as the "strong side," in contrast to the other "weak side").

The peak speed test on the treadmill. The participants warmed up for the V1 peak speed test with a standardized 15 -min procedure involving $10 \mathrm{~min}$ of skiing at $\sim 70 \%-85 \%$ of $\dot{\mathrm{V}}_{2 \max }$ followed by four 6-s sprints during the final $5 \mathrm{~min}$. After a 3-min rest, the treadmill incline was set at $7^{\circ}$ and the initial speed at $12 \mathrm{~km} \cdot \mathrm{h}^{-1}$ (achieved by linear acceleration for $10 \mathrm{~s}$ ), after which the speed was increased by $1 \mathrm{~km} \cdot \mathrm{h}^{-1}$ every $10 \mathrm{~s}$ until exhaustion was reached (as determined by the investigator when the participant fell more than $1.5 \mathrm{~m}$ behind the front of the treadmill [36]). $V_{\text {peak }}$ was calculated by linear interpolation using the formula: $V_{\text {peak }}=V_{f}+[(t / 10) \Delta V]$, where $V_{f}$ was the speed during the last workload completed, $t$ was the duration of this last workload (s), and $\Delta V$ was the difference in speed during the last two workloads. To ensure that each skier performed maximally, their $V_{\text {peak }}$ determined here was compared to previous results using the same approach and found to be similar in all cases.

The roller skis and treadmill. The Pro-Ski S2 rollerski used (Sterners, Nyhammar, Sweden) exhibited a resistance friction coefficient of $\mu_{R}=0.016$, as measured on the treadmill surface with an instrument specifically designed for this purpose (1). The treadmill (Rodby, Södertalje, Sweden; belt dimension $3.3 \times 2.5 \mathrm{~m}$ ) was large enough to allow roller skiing with the skating technique, and all subjects were accustomed to roller skiing at high speeds on this treadmill as part of both their training and testing. During all testing, the subjects were secured with a safety harness connected to an emergency brake suspended above the treadmill.

Force measurements. All subjects used carbon-fiber racing poles specially constructed for force measurements. These poles were adjustable, which enabled the subjects to choose their own preferred individual length. Ground reaction force of the pole, directed along its length, was monitored by a strain gauge force transducer mounted directly below the pole grip (Hottinger Baldwin Messtechnik GmbH, Darmstadt, Germany). This transducer had a mass of $60 \mathrm{~g}$ and was installed in a lightweight $(75 \mathrm{~g})$ aluminum tube.

Plantar ski reaction forces were recorded at $100 \mathrm{~Hz}$ by a Pedar mobile system (Novel GmbH, Munich, Germany) 
consisting of two insoles (containing 99 capacitive sensors each) that measured pressure distribution, a data logger with an internal flash (32 MB), and cable sets. The insoles were calibrated with a computerized Pedar device, using homogenous air pressure. The system for measuring pole and plantar forces was as described by Holmberg et al. (13). With our system, the mean absolute values differed by approximately $2.3 \%$ (plantar forces) and $2.8 \%$ (pole forces), respectively, from those provided by an AMTI force plate (AMTI, Watertown, MA).

Three-dimensional kinematics. The 3D kinematics of the whole body, poles, roller skis, and treadmill were captured by a Vicon MX13 motion system (Vicon Peak, Oxford, UK) involving eight cameras sampling at $250 \mathrm{~Hz}$. The global coordinate system was right-handed and defined as follows: the incline of the treadmill was set to $0^{\circ} ; x$ axis $=$ side to side across the treadmill, $y$ axis $=$ longitudinal axis of the treadmill (i.e., the direction of motion), $z$ axis $=$ perpendicular to the ground. A kinematic model (Plug-InGait; Vicon Peak) was used to attach 39 reflective markers (14 $\mathrm{mm}$ in diameter) onto bony anatomical landmarks on the skier's body.

Twelve additional reflective markers were placed on the poles (two each), roller skis (two each), and treadmill (four markers). The pole markers (fixed onto the lateral aspect with double-sided tape and fixed with additional tape around the pole to avoid movement) were placed at the top $(1 \mathrm{~cm}$ below the bottom of the grip) and $5 \mathrm{~cm}$ above the tip. Markers were placed on the left and right sides at the front and rear of the treadmill, parallel to the direction of skiing, to provide exact information about the incline and position of the treadmill plane in space. Two markers were placed along the midline of each roller ski, one in front of the binding and one behind the front wheel. The distance between the pivot point of the binding point (where the $\mathrm{XC}$ boot is fixed to the binding) and the marker placed in front of the binding was measured manually $(10 \mathrm{~cm})$ to calculate the location of the pivot point of the binding from the coordinates of the two markers placed on the roller ski (34).

Collection and analysis of biomechanical data. All variables were assessed and calculated for both sides of the body. For each variable, the values of six successive cycles at each speed $\left(13,14,15\right.$, and $\left.16 \mathrm{~km} \cdot \mathrm{h}^{-1}\right)$ were calculated, and the mean of these six cycles was used for analysis. Pole forces were recorded using a telemetric system (TeleMyo $2400 \mathrm{~T}$ G2; Noraxon, Scottsdale, AZ), as well as simultaneously recorded together with 3D kinematic data using the Nexus 1.6 software (Vicon) at a sampling rate of $1500 \mathrm{~Hz}$. The Noraxon system involved a default time shift of $50 \mathrm{~ms}$ for the analog signal of pole force, so that the 3D data were corrected accordingly before calculating force and kinematic values using a MatLab routine. Processing of all data was performed with the Vicon BodyBuilder (Vicon) and IKE-master software (IKE-Software Solutions, Salzburg, Austria).

Determination of cycle characteristics. Cycle characteristics (cycle time, cycle length, and cycle rate) and the phases during poling action and leg push-off (ground contact time, swing time, coordination of leg and arm forces, etc.) were calculated from the plantar and pole forces. The position of the marker on the pole tip with respect to the pivot point was used to determine the forward distance covered by the pole at pole plant. The leg "forestep" was determined as the distance covered by the pivot point in the direction of skiing from the end of leg push-off to the next setting down of the roller ski.

Determination of pole and leg angles for calculation of force components. As illustrated in Figure 1A,
A

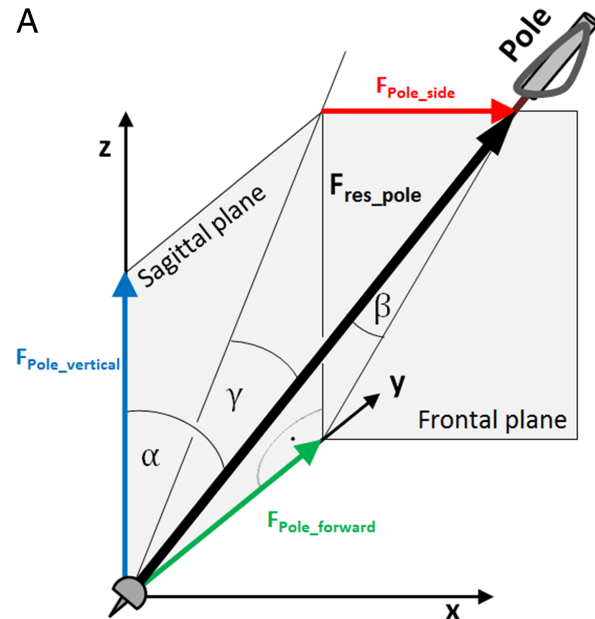

B

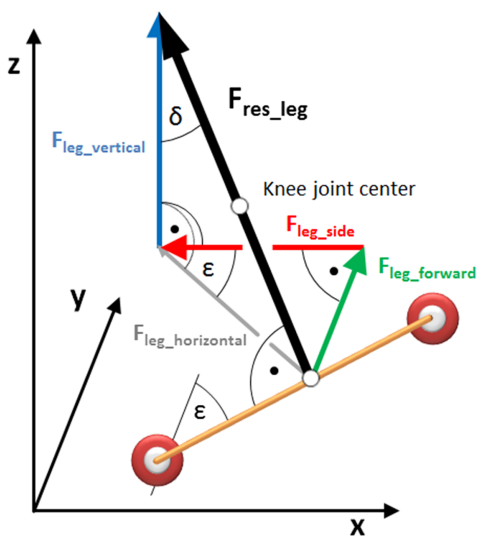

C

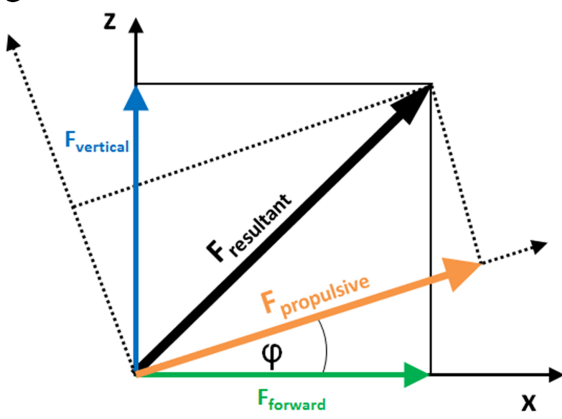

$\mathrm{F}_{\text {propulsive }}=\cos \varphi \cdot \mathrm{F}_{\text {forward }}+\sin \varphi \cdot \mathrm{F}_{\text {vertical }}$

FIGURE 1-Illustration of the coordinate system $\left(x\right.$ : side to side across the treadmill; $y$ : long side of the treadmill at an incline of $0^{\circ}$; $z$ : vertical direction). A. Calculation of the pole angles in the vertical ( $\alpha)$ forward (along the $y$ axis) $(\beta)$ and sideward $(\gamma)$ directions. B. Illustration of the leg angles determined and the force components according to the leg push-off model. The angle $\delta$ is the angle between the directions of the resultant leg force

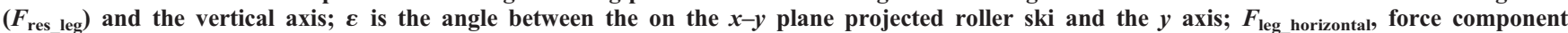

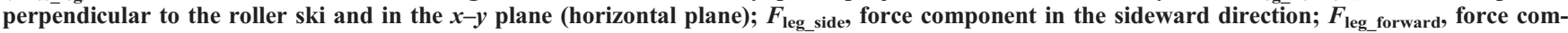
ponent in the direction of the $y$ axis. C. Illustration of the rotation (grade of the treadmill $\phi$ ) of the vertical and forward force component along the $x$ axis. Note that the vertical and propulsive components are not orthogonal to one another. 
the pole angle with respect to the vertical axis $(\alpha)$ was calculated from the pole vector (from the top to the tip marker) and the $z$ axis. For calculation of the forward pole angle, the top and tip markers were first projected onto the $x-z$ plane (frontal plane), and thereafter, the angle between the two pole and two projected markers was calculated $(\beta)$. For the calculation of the sideward pole angle, the top and tip markers were first projected onto the $y-z$ plane (sagittal plane), and the angle between the two pole and two projected markers was then calculated $(\gamma)$.

As illustrated in Figure 1B, for the determination of the force components in the vertical, sideward, and forward directions, the following angles were calculated: 1) the angle of the resultant force with respect to the vertical axis ( $\delta$ ) by (a) projecting one roller ski marker onto the plane perpendicular to the roller ski and passing through the center of the knee joint, (b) calculating the vector between this new point and the center of the knee joint (i.e., the vector perpendicular to the roller ski and through the knee joint center), and (c) determining the angle between this vector perpendicular to the roller ski and the $z$ axis; and 2) the angle between the projection of the roller ski onto the $x-y$ plane (horizontal) and the $y$ axis (horizontal direction) $(\varepsilon)$.

Within the coordinate system of the treadmill plane, the following additional angles were defined: 1) the angle of the roller ski (indicated by its two markers) with respect to the direction of skiing (determined from the two treadmill markers along this direction) (the $\mathrm{V}$-angle), and 2) the edging angle, that is, the angle between the vector of the resultant force (perpendicular to the roller ski; see the calculation above) and the vector perpendicular to the treadmill surface.

Calculation of components of pole forces. The vertical pole force was determined as the resultant pole force multiplied by the cosine of the angle of the pole with respect to the vertical $(z)$ axis $(\alpha)$. The horizontal (along the $y$ axis) and sideward (along the $x$ axis) pole forces were calculated as the resultant pole force multiplied by the sine of the angle of the pole relative to the forward $(\beta)$ or sideward $(\gamma)$ direction, respectively. The propulsive force (in the direction of skiing) was calculated by rotating (by the grade of the treadmill $\varphi$ ) the vertical and horizontal force components around the $x$ axis.

$$
F_{\text {pole_propulsive }}=F_{\text {pole_forward }} \cos (\varphi)+F_{\text {pole_vertical }} \sin (\varphi)
$$

It should be noted that, on an incline, the vertical and propulsive components are not orthogonal to one another; therefore, interdependencies between these two components are provided. From a mechanistic perspective, the force component acting against gravity (vertical) and the component in the direction of skiing (propulsive) are of major relevance here; although the component perpendicular to the plane of the treadmill (orthogonal to the propulsive and sideward components) is of minor interest in the current study, this might be of importance for the calculations of friction.
Calculation of components of leg forces. The leg force in the vertical direction was calculated by multiplying $F_{\text {res_leg }}$ by the cosine of the angle with respect to vertical $(\delta)$

$$
F_{\text {leg_vertical }}=F_{\text {res_leg }} \cos (\delta)
$$

The force in the horizontal plane $\left(F_{\text {leg horizontal }}\right)$ was calculated by multiplying the resultant leg force $\left(F_{\text {res_leg }}\right)$ by the sine of the angle with respect to vertical $(\delta)$

$$
F_{\text {leg_horizontal }}=F_{\text {res_leg }} \sin (\delta)
$$

Finally, the sideward ( $\left.F_{\text {leg_side }}\right)$ and forward $\left(F_{\text {leg_forward }}\right)$ leg force components were calculated by multiplying $F_{\text {leg_horizontal }}$ by the cosine, respectively, sine of the angle between the roller ski and the direction of skiing $(\varepsilon)$ :

$$
\begin{gathered}
F_{\text {leg_side }}=F_{\text {leg_horizontal }} \cos (\varepsilon) \\
F_{\text {leg_forward }}=F_{\text {leg_horizontal }} \sin (\varepsilon)
\end{gathered}
$$

The propulsive component of leg force was calculated using a rotation $(\varphi$, the incline of the treadmill; Fig. 1C) similar to that described above for the proplusive pole force:

$$
F_{\text {leg_propulsive }}=F_{\text {leg_forward }} \cos (\varphi)+F_{\text {leg_vertical }} \sin (\varphi)
$$

With respect to the above, remember that, on an incline, the vertical and propulsive components are not orthogonal. The resultant, vertical, sideward, and propulsive force impulses for the pole and leg on the "strong" and "weak" sides and the total resultant and propulsive force impulses (the sum of the force impulses of both poles and both legs) were calculated. The average cycle force and average propulsive cycle force (APCF) were determined by dividing the total force impulse, respectively, propulsive force impulse, by cycle time. Power output in the skiing direction was determined as APCF multiplied by skiing speed $\left(\mathrm{m} \cdot \mathrm{s}^{-1}\right)$. The propulsive force component (expressed as percentage of the resultant force) represents the effectiveness index. This index was calculated separately for the poles and legs and for the "strong" and "weak" sides, as well as for the poles and legs combined (overall effectiveness).

Statistical analyses. All data were normally distributed (as assessed by the Shapiro-Wilk test) and are presented as means \pm SD. To determine the relationships between kinetic and 3D kinematic variables at the speeds of 13, 14, 15, and $16 \mathrm{~km} \cdot \mathrm{h}^{-1}$ to $V_{\text {peak }}$ with V1 skating, Pearson's productmoment correlations were calculated. One-way (four speeds) and two-way (four speeds and "strong" vs "weak" side) ANOVA with repeated-measures and Bonferroni post hoc analysis were conducted. In addition, the values obtained were evaluated further by calculating the effect size $\left({ }_{\mathrm{p}} \eta^{2}\right)$ and statistical power. For all analyses, the level of statistical significance was set at $\alpha=0.05$. All statistical analyses were carried out using SPSS 22.0 Software (SPSS, Inc., 
Chicago, IL) and Office Excel 2010 (Microsoft Corporation, Redmond, WA).

\section{RESULTS}

Description of the $\mathbf{V} \mathbf{1}$ technique and the influence of speed. Table 1 documents the kinematic variables associated with cycle characteristics and timing for the "strong" and "weak" sides at the four submaximal speeds examined. The cycle rate increased by $20 \%$, whereas the poling and leg push-off times both decreased by $21 \%$ as the speed was elevated (all $P<0.001$ ). Cycle length was greater at 14 and 15 than at $13 \mathrm{~km} \cdot \mathrm{h}^{-1}(P<0.001)$, with no difference between 13 and $16 \mathrm{~km} \cdot \mathrm{h}^{-1}$. The pole on the "weak side" was set earlier $(\sim 30 \mathrm{~ms})$ and left the ground was sooner $(\sim 75 \mathrm{~ms})$ than the one on the "strong side," resulting in a shorter poling time on the "weak side" (all $P<0.001$ ). For the "strong side" leg, the poling phase was terminated approximately $175 \mathrm{~ms}$ earlier than the leg push-off phase.

Leg push-off time was longer for the "weak side" than the "strong side" ( $\sim 57 \mathrm{~ms}, P<0.001)$, with a more pronounced reduction in the former as the speed was enhanced $(P<0.01)$. The set of the "weak side" leg and end of the "strong side" push-off overlapped by $\sim 115 \mathrm{~ms}$, and the set of the "strong side" leg and end of the "weak side" leg push-off overlapped by $\sim 55 \mathrm{~ms}$. This overlap was more pronounced in the former case $(P<0.001)$, with an interaction effect toward a greater reduction in the overlap time in the latter $(P<0.001)$. At 14 and $16 \mathrm{~km} \cdot \mathrm{h}^{-1}$, one and four skiers, respectively, began to jump during the transition from the end of the "weak" leg push-off to the set of the "strong side" leg, with a flight time of $35 \pm 24 \mathrm{~ms}$ (range $=19-71 \mathrm{~ms}$ ) at $16 \mathrm{~km} \cdot \mathrm{h}^{-1}$.

Table 2 presents the angles and distances associated with the V1 skating. At the time of pole plant, the "strong side" pole was set in front of the pivot point of the "strong side" leg $(3.6-6.0 \mathrm{~cm})$ at the speeds of $13-15 \mathrm{~km} \cdot \mathrm{h}^{-1}$, whereas the "weak side" pole was set behind this point $(-6.9$ to $-15.9 \mathrm{~cm})$ at all four submaximal speeds $(P<0.001)$. This difference was also reflected in the observation that the "strong side" pole was set straighter in both the forward $\left(\beta=\sim 8^{\circ}\right.$ vs $\left.22^{\circ}\right)$ and the sideward $\left(\gamma=\sim 3.5^{\circ}\right.$ vs $\left.22^{\circ}\right)$ directions than the "weak side" pole (both $P<0.001$ ). With increasing speed, the poles were planted at a greater angle with respect to vertical and further toward the rear of the treadmill with respect to the body, especially when approaching $16 \mathrm{~km} \cdot \mathrm{h}^{-1}$, the highest speed examined here $(P<0.001)$.

The forestep was greater for the "weak side" than the "strong side" leg ( $\sim 54$ vs $33 \mathrm{~cm}, P<0.001)$, with a slight elevation with increasing speed, especially for the "strong side" leg $(P<0.05)$. The edging angle upon initiation of leg ground contact was smaller for the "strong" than the "weak side" ( $\delta=\sim 6^{\circ}$ vs $\left.9^{\circ}, P<0.01\right)$ and increased with speed only on the "weak side" $(P<0.001)$. The edging angle at the end of leg push-off was the same on both sides, with a more pronounced rise with increasing speed on the "strong side" leg $(P<0.05)$. All skiers edged their skis immediately

TABLE 1. Cycle characteristics associated with V1 skating at four submaximal speeds $(N=15)$.

\begin{tabular}{|c|c|c|c|c|c|c|c|c|}
\hline \multirow[b]{2}{*}{ Parameter } & \multicolumn{4}{|c|}{ Speed $\left(\mathrm{km} \cdot \mathrm{h}^{-1}\right)$} & \multirow[b]{2}{*}{$\boldsymbol{F}$} & \multirow[b]{2}{*}{$P$} & \multirow{2}{*}{$\begin{array}{c}\text { Effect } \\
\text { Size }{ }_{p} \eta^{2}\end{array}$} & \multirow{2}{*}{$\begin{array}{l}\text { Test } \\
\text { Power }\end{array}$} \\
\hline & 13 & 14 & 15 & 16 & & & & \\
\hline Cycle rate $(\mathrm{Hz})$ & $0.88 \pm 0.03^{*}$ & $0.92 \pm 0.04^{*}$ & $0.98 \pm 0.04^{\star}$ & $1.06 \pm 0.05^{\star}$ & $F_{3,12}=85^{a}$ & $<0.001$ & 0.95 & 1.0 \\
\hline Cycle length (m) & $4.10 \pm 0.15^{2,3}$ & $4.24 \pm 0.18$ & $4.25 \pm 0.16$ & $4.19 \pm 0.18$ & $F_{3,12}=13^{a}$ & $<0.001$ & 0.76 & 1.0 \\
\hline Poling time on "strong side" (s) & $0.47 \pm 0.02^{\star}$ & $0.44 \pm 0.02^{*}$ & $0.40 \pm 0.02^{*}$ & $0.37 \pm 0.02^{*}$ & $F_{3,12}=187^{a}$ & $<0.001$ & 0.98 & 1.0 \\
\hline Poling time on "weak side" (s) & $0.42 \pm 0.02^{\star}$ & $0.40 \pm 0.03^{*}$ & $0.36 \pm 0.03^{*}$ & $0.33 \pm 0.03^{\star}$ & $F_{3,12}=1.4^{c}$ & NS & & \\
\hline Swing time for "strong side" pole (s) & $0.67 \pm 0.04^{3,4}$ & $0.65 \pm 0.04^{3,4}$ & $0.62 \pm 0.04^{*}$ & $0.57 \pm 0.04^{*}$ & $\begin{array}{l}F_{3,12}=38^{a} \\
F_{1,14}=43^{b}\end{array}$ & $\begin{array}{l}<0.001 \\
<0.001\end{array}$ & $\begin{array}{l}0.91 \\
0.75\end{array}$ & $\begin{array}{l}1.0 \\
1.0\end{array}$ \\
\hline Swing time for "weak side" pole (s) & $0.72 \pm 0.05^{3,4}$ & $0.70 \pm 0.05^{3,4}$ & $0.66 \pm 0.05^{\star}$ & $0.61 \pm 0.05^{\star}$ & $F_{3,12}=1.5^{c}$ & NS & & \\
\hline $\begin{array}{l}\text { Difference in time between the instants of pole } \\
\text { plant on the "strong" and "weak" sides (ms) }\end{array}$ & $34 \pm 23$ & $35 \pm 28$ & $28 \pm 23$ & $20 \pm 20^{*}$ & $F_{3,12}=7.3^{a}$ & $<0.01$ & 0.65 & 0.93 \\
\hline $\begin{array}{l}\text { Difference in time between the instants of pole-off on the "strong" } \\
\text { and "weak" sides (ms) }\end{array}$ & $85 \pm 36^{3,4}$ & $78 \pm 37$ & $69 \pm 33$ & $63 \pm 29$ & $\begin{array}{l}F_{1,14}=42^{b} \\
F_{3,12}=1.5^{c}\end{array}$ & $\begin{array}{l}<0.001 \\
\text { NS }\end{array}$ & 0.75 & 1.0 \\
\hline Push-off time for "strong side" leg (s) & $0.64 \pm 0.04^{*}$ & $0.60 \pm 0.03^{*}$ & $0.56 \pm 0.03^{*}$ & $0.52 \pm 0.03^{*}$ & $\begin{array}{l}F_{3,12}=116^{a} \\
F_{1,14}=28^{b}\end{array}$ & $\begin{array}{l}<0.001 \\
<0.001\end{array}$ & $\begin{array}{l}0.97 \\
0.67\end{array}$ & $\begin{array}{l}1.0 \\
1.0\end{array}$ \\
\hline Push-off time for "weak side" leg (s) & $0.71 \pm 0.03^{\star}$ & $0.67 \pm 0.04^{*}$ & $0.62 \pm 0.05^{\star}$ & $0.55 \pm 0.04^{*}$ & $F_{3,12}=10^{c}$ & $<0.01$ & 0.71 & 0.98 \\
\hline $\begin{array}{l}\text { Time elapsed between initial ground contact by "weak side" leg } \\
\text { and end of push-off by "strong side" leg (ms) }\end{array}$ & $126 \pm 15^{3,4}$ & $120 \pm 18^{3,4}$ & $113 \pm 15$ & $108 \pm 13$ & $F_{3,12}=60^{a}$ & $<0.001$ & 0.94 & 1.0 \\
\hline $\begin{array}{l}\text { Time elapsed between initial ground contact by "strong side" leg } \\
\text { and end of push-off by "weak side" leg (ms) }\end{array}$ & $85 \pm 31^{3,4}$ & $73 \pm 40^{3,4}$ & $48 \pm 42^{*}$ & $16 \pm 42^{*}$ & $\begin{array}{l}F_{1,14}=44^{b} \\
F_{3,12}=16^{c}\end{array}$ & $\begin{array}{l}<0.001 \\
<0.001\end{array}$ & $\begin{array}{l}0.76 \\
0.80\end{array}$ & $\begin{array}{l}1.0 \\
1.0\end{array}$ \\
\hline $\begin{array}{l}\text { Time elapsed between end of poling phase and end of leg } \\
\text { push-off on "strong side" (ms) }\end{array}$ & $164 \pm 33^{2}$ & $187 \pm 30$ & $175 \pm 32$ & $171 \pm 30$ & $F_{3,12}=4^{a}$ & $<0.05$ & 0.49 & 0.67 \\
\hline
\end{tabular}

The values presented are means \pm SD. $F$ and $P$ values were obtained by two-way ANOVA $(4 \times 2$ : skiing speed $\times$ body side [strong vs weak]).

NS, Not statistically significant.

*Significantly different from all other speeds.

${ }^{2}$ Significantly different from $14 \mathrm{~km} \cdot \mathrm{h}^{-1}$.

${ }^{3}$ Significantly different from $15 \mathrm{~km} \cdot \mathrm{h}^{-1}$

${ }^{4}$ Significantly different from $16 \mathrm{~km} \cdot \mathrm{h}^{-1}$

${ }^{a}$ Main effect between skiing speeds.

${ }^{b}$ Main effect between body sides (strong vs weak).

${ }^{c}$ Interactive effect: skiing speed-body side. 


\begin{tabular}{|c|c|c|c|c|c|c|c|c|}
\hline \multirow[b]{2}{*}{ Parameter } & \multicolumn{4}{|c|}{ Speed $\left(\mathbf{k m} \cdot \mathrm{h}^{-1}\right)$} & \multirow[b]{2}{*}{$F$} & \multirow[b]{2}{*}{$P$} & \multirow{2}{*}{$\begin{array}{l}\text { Effect } \\
\text { Size }_{p} \eta^{2}\end{array}$} & \multirow{2}{*}{$\begin{array}{l}\text { Test } \\
\text { Power }\end{array}$} \\
\hline & 13 & 14 & 15 & 16 & & & & \\
\hline Forestep, "strong side" leg (cm) & $30 \pm 6^{3,4}$ & $33 \pm 7$ & $34 \pm 6$ & $35 \pm 6$ & $\begin{array}{l}F_{3,12}=5^{a} \\
F_{1,14}=129^{b}\end{array}$ & $\begin{array}{l}<0.05 \\
<0.001\end{array}$ & $\begin{array}{l}0.55 \\
0.90\end{array}$ & $\begin{array}{l}0.79 \\
1.0\end{array}$ \\
\hline Forestep, "weak side" leg (cm) & $52 \pm 7$ & $54 \pm 7$ & $55 \pm 7$ & $56 \pm 9$ & $F_{3,12}=0.8^{c}$ & NS & & \\
\hline $\begin{array}{l}\text { Distance from the pole to pivot point at the instant of pole plant } \\
\text { on the "strong side" }(\mathrm{cm})\end{array}$ & $5.5 \pm 10.2$ & $3.6 \pm 9.0$ & $6.0 \pm 82$ & $-6.9 \pm 7.7^{\star}$ & $\begin{array}{l}F_{3,12}=18^{a} \\
F_{1,14}=16^{b}\end{array}$ & $\begin{array}{l}<0.001 \\
<0.001\end{array}$ & $\begin{array}{l}0.82 \\
0.54\end{array}$ & $\begin{array}{l}1.0 \\
0.96\end{array}$ \\
\hline $\begin{array}{l}\text { Distance from the pole to pivot point at the instant of pole plant on } \\
\text { the "weak side" }(\mathrm{cm})\end{array}$ & $-7.2 \pm 8.1$ & $-6.9 \pm 10.4$ & $-10.0 \pm 10.1$ & $-15.9 \pm 10.6^{*}$ & $F_{3,12}=3^{c}$ & NS & & \\
\hline $\begin{array}{l}\text { Pole angle in the skiing direction at the instant of pole plant } \\
\text { on the "strong side" }\left({ }^{\circ}\right)\end{array}$ & $6 \pm 4$ & $7 \pm 4$ & $8 \pm 3^{\star}$ & $11 \pm 3^{*}$ & $\begin{array}{l}F_{3,12}=22^{a} \\
F_{1,14}=281^{b}\end{array}$ & $\begin{array}{l}<0.001 \\
<0.001\end{array}$ & $\begin{array}{l}0.84 \\
0.95\end{array}$ & $\begin{array}{l}1.0 \\
1.0\end{array}$ \\
\hline $\begin{array}{l}\text { Pole angle in the skiing direction at the instant of pole plant } \\
\text { on the "weak side" ( })\end{array}$ & $21 \pm 2$ & $21 \pm 4$ & $22 \pm 4^{*}$ & $24 \pm 4^{\star}$ & $F_{3,12}=0.5^{c}$ & NS & & \\
\hline Sideward pole angle, "strong side" $\left(^{\circ}\right)$ & $3 \pm 2$ & $3 \pm 2$ & $4 \pm 2$ & $4 \pm 2$ & $\begin{array}{l}F_{3,12}=7^{a} \\
F_{1,14}=449^{b}\end{array}$ & $\begin{array}{l}<0.01 \\
<0.001\end{array}$ & $\begin{array}{l}0.65 \\
0.97\end{array}$ & $\begin{array}{l}0.93 \\
1.0\end{array}$ \\
\hline Sideward pole angle, "weak side" $\left({ }^{\circ}\right)$ & $20 \pm 3^{3,4}$ & $21 \pm 3^{4}$ & $22 \pm 3$ & $23 \pm 3$ & $F_{3,12}=8^{c}$ & $<0.01$ & 0.67 & 0.96 \\
\hline Edging angle upon initial ground contact on the "strong side" $\left({ }^{\circ}\right)$ & $6 \pm 2$ & $6 \pm 2$ & $6 \pm 2$ & $6 \pm 2$ & $\begin{array}{l}F_{3,12}=7^{a} \\
F_{1,14}=12^{b}\end{array}$ & $\begin{array}{l}<0.01 \\
<0.01\end{array}$ & $\begin{array}{l}0.64 \\
0.45\end{array}$ & $\begin{array}{l}0.92 \\
0.89\end{array}$ \\
\hline Edging angle upon initial ground contact on the "weak side" $\left(^{\circ}\right)$ & $7 \pm 2$ & $7 \pm 3$ & $9 \pm 2^{*}$ & $10 \pm 2^{*}$ & $F_{3,12}=25^{c}$ & $<0.001$ & 0.86 & 1.0 \\
\hline Edging angle at the end of ground contact on the "strong side" $\left(^{\circ}\right)$ & $38 \pm 2^{*}$ & $39 \pm 2^{*}$ & $40 \pm 1$ & $41 \pm 2$ & $\begin{array}{l}F_{3,12}=23^{a} \\
F_{1,14}=3.4^{b}\end{array}$ & $\begin{array}{c}<0.001 \\
\text { NS }\end{array}$ & $\begin{array}{l}0.85 \\
0.49\end{array}$ & $\begin{array}{l}1.0 \\
0.67\end{array}$ \\
\hline Edging angle at the end of ground contact on the "weak side" $\left({ }^{\circ}\right)$ & $38 \pm 2$ & $38 \pm 2$ & $39 \pm 2$ & $39 \pm 3$ & $F_{3,12}=3.8^{c}$ & $<0.05$ & & \\
\hline Ski angle, "strong side" $\left({ }^{\circ}\right)$ & $19 \pm 1$ & $19 \pm 1$ & $19 \pm 1$ & $19 \pm 1$ & $\begin{array}{l}F_{3,12}=1.1^{a} \\
F_{1,14}=4.4^{b}\end{array}$ & $\begin{array}{l}\text { NS } \\
\text { NS }\end{array}$ & & \\
\hline Ski angle, "weak side" $\left({ }^{\circ}\right)$ & $18 \pm 2$ & $17 \pm 2$ & $17 \pm 2$ & $17 \pm 2$ & $F_{3,12}=2.7^{c}$ & NS & & \\
\hline
\end{tabular}

The values presented are means \pm SD. $F$ and $P$ values were obtained by two-way ANOVA $(4 \times 2$ : skiing speed $\times$ body side [strong vs weak]).

NS, not statistically significant.

${ }^{\star}$ Significantly different from all other speeds.

${ }^{2}$ Significantly different from $14 \mathrm{~km} \cdot \mathrm{h}^{-1}$.

${ }^{3}$ Significantly different from $15 \mathrm{~km} \cdot \mathrm{h}^{-1}$

${ }^{4}$ Significantly different from $16 \mathrm{~km} \cdot \mathrm{h}^{-1}$.

${ }^{a}$ Main effect between skiing speeds.

${ }^{b}$ Main effect between body side (strong vs weak)

${ }^{c}$ Interactive effect: skiing speed-body side.

after set down. The edging angle during the ground contact phase increased almost linearly with time, especially on the "strong side," with a less pronounced increase on the "weak side" for certain of the slower skiers during the first half of this phase. The angle between the ski and direction of skiing $(\varepsilon)$ was equal on both sides and remained constant at approximately $18^{\circ}$ at the different speeds.

Pole and leg kinetics. The pole and leg forces at the different speeds are presented in Table 3. Although the peak resultant pole force for the "strong" and "weak" sides combined rose (from 227 to $259 \mathrm{~N}, P<0.01$ ), all other components of the pole force declined (all $P<0.01-0.001$ ) with increasing speed. The peak pole force, impulse of pole force, and propulsive impulse of pole force and vertical impulses of the pole force were greater for the "strong side" than for the "weak side" (all $P<0.001-0.01$ ), with only the sideward impulse of the pole force being greater for the "weak side" $(P<0.001)$. The peak pole force was $35 \%-$ $40 \%$ of body weight on the "strong side" and $27 \%-35 \%$ of body weight on the "weak side."

The peak resultant leg force was greater on the "strong side" ( $\sim 1070$ vs $978 \mathrm{~N}, P<0.01)$, whereas all other force components calculated were equal for both sides. With increasing speed, all parameters of leg force calculated were diminished (all $P<0.05-0.001$ ), more so on the "weak side" $(P<0.001-0.01)$ in the case of the impulses of resultant, propulsive, and vertical leg forces. Peak leg force was $28 \%-36 \%$ more than body weight on the "strong side" and $18 \%-26 \%$ more than body weight on the "weak side."
Relative contributions of the upper and lower body, total forces, and effectiveness. Although the total impulse of resultant force was reduced $(-16 \%)$ with increasing speed $(P<0.001)$, the average cycle force remained constant and the APCF rose slightly $(+8.7 \%, P<0.05)$. Power output in the direction of skiing (using the total propulsive force component) increased with speed $(+33 \%$, $P<0.001$ ), with the maximal individual value being $716 \mathrm{~W}$ at $16 \mathrm{~km} \cdot \mathrm{h}^{-1}$ (Table 4 ).

The poles exhibited higher effectiveness than the legs $(\sim 59 \%$ vs $11 \%, P<0.001)$, with the "strong side" pole being less effective than the "weak side" ( $\sim 56 \%$ vs $65 \%$, $P<0.001)$ and the opposite pattern in the case of the legs $(\sim 12 \%$ vs $10 \%, P<0.05)$. The effectiveness for all variables rose with increasing speed (all $P<0.01-0.001$ ), with an interaction toward a more pronounced elevation for the "weak side" leg $(P<0.05)$. The proportion of the total propulsion generated by the poles (approximately 44\%) was independent of speed. Leg forces contributed approximately $89 \%$ of the vertical and $93 \%$ of the sideward force, again independent of speed, with no difference between the "strong" and "weak" sides.

Figure 2 illustrates the time course of the resultant and propulsive components for the poles and legs on the "strong" and "weak" sides during three consecutive cycles of skiing.

Correlations to $\boldsymbol{V}_{\text {peak. }}$. The mean $V_{\text {peak }}$ during the V1 skating test was $17.8 \pm 0.8 \mathrm{~km} \cdot \mathrm{h}^{-1}\left(\right.$ range $\left.=16.7-19.2 \mathrm{~km} \cdot \mathrm{h}^{-1}\right)$ and the mean duration was $68 \pm 8 \mathrm{~s}$ (range $=57-82 \mathrm{~s}$ ). The delta value between the instants of pole plant on the "weak" 
TABLE 3. Pole and leg forces associated with V1 skating at four submaximal speeds $(N=15)$

\begin{tabular}{|c|c|c|c|c|c|c|c|c|c|}
\hline & \multirow[b]{2}{*}{ Parameter } & \multicolumn{4}{|c|}{ Speed $\left(\mathrm{km} \cdot \mathrm{h}^{-1}\right)$} & \multirow[b]{2}{*}{$F$} & \multirow[b]{2}{*}{$P$} & \multirow{2}{*}{$\begin{array}{c}\text { Effect } \\
\text { Size }{ }_{p} \eta^{2}\end{array}$} & \multirow{2}{*}{$\begin{array}{c}\text { Test } \\
\text { Power }\end{array}$} \\
\hline & & 13 & 14 & 15 & 16 & & & & \\
\hline \multirow[t]{15}{*}{ Pole forces } & Peak "strong side" (N) & $276 \pm 64^{*}$ & $298 \pm 59$ & $301 \pm 62$ & $307 \pm 67$ & $F_{3,12}=8^{a}$ & $<0.01$ & 0.70 & 0.92 \\
\hline & & & & & & $F_{1,14}=23^{b}$ & $<0.001$ & 0.66 & 0.99 \\
\hline & Peak "weak side" (N) & $177 \pm 26^{3,4}$ & $192 \pm 40^{4}$ & $205 \pm 38$ & $211 \pm 44$ & $F_{3,12}=1.5^{c}$ & NS & & \\
\hline & Impulse "strong side" (N·s) & $64 \pm 15^{4}$ & $64 \pm 14^{3,4}$ & $61 \pm 14^{2,4}$ & $56 \pm 13^{\star}$ & $F_{3,12}=21^{a}$ & $<0.001$ & 0.85 & 1.0 \\
\hline & & & & & & $F_{1,14}=23^{b}$ & $<0.001$ & 0.64 & 0.99 \\
\hline & Impulse "weak side" (N·s) & $43 \pm 8^{3,4}$ & $41 \pm 9^{3,4}$ & $38 \pm 8^{*}$ & $33 \pm 7^{\star}$ & $F_{3,12}=0.8^{c}$ & NS & & \\
\hline & Propulsive impulse "strong side" $(\mathrm{N} \cdot \mathrm{s})$ & $35 \pm 8^{4}$ & $36 \pm 8^{3,4}$ & $34 \pm 7^{2,4}$ & $32 \pm 7^{*}$ & $F_{3,12}=19^{a}$ & $<0.001$ & 0.84 & 1.0 \\
\hline & 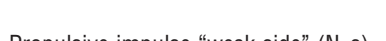 & 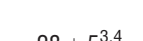 & & & & $F_{1,14}=11^{b}$ & $<0.01$ & 0.46 & 0.87 \\
\hline & Propulsive impulse "weak side" (N·s) & $28 \pm 5^{3,4}$ & $27 \pm 6^{3,4}$ & $25 \pm 6^{\star}$ & $22 \pm 5^{\star}$ & $F_{3,12}=1.9^{c}$ & NS & & \\
\hline & Sideward impulse "strong side" (N-s) & $4 \pm 2$ & $4 \pm 2$ & $4 \pm 2$ & $4 \pm 2$ & $F_{3,12}=9.4^{a}$ & $<0.01$ & 0.72 & 0.97 \\
\hline & & & & & & $F_{1,14}=75^{b}$ & $<0.001$ & 0.85 & 1.0 \\
\hline & Sideward impulse "weak side" (N·s) & $15 \pm 4$ & $15 \pm 4$ & $14 \pm 4$ & $13 \pm 3^{*}$ & $F_{3,12}=11^{c}$ & $<0.001$ & 0.76 & 0.99 \\
\hline & Vertical impulse "strong side" $(\mathrm{N} \cdot \mathrm{S})$ & $56 \pm 14^{4}$ & $56 \pm 13^{3,4}$ & $52 \pm 12^{2,4}$ & $48 \pm 11^{\star}$ & $F_{3,12}=20^{a}$ & $<0.001$ & 0.84 & 1.0 \\
\hline & & & & & & $F_{1,14}=43^{b}$ & $<0.001$ & 0.77 & 1.0 \\
\hline & Vertical impulse "weak side" (N·s) & $33 \pm 6^{3,4}$ & $31 \pm 8^{3,4}$ & $28 \pm 6^{\star}$ & $24 \pm 5^{\star}$ & $F_{3,12}=0.7^{c}$ & NS & & \\
\hline \multirow[t]{14}{*}{ Leg forces } & Peak "strong side" (N) & $1090 \pm 140$ & $1085 \pm 162$ & $1069 \pm 169$ & $1022 \pm 182^{*}$ & $F_{3,12}=3.7^{\mathrm{a}}$ & $<0.05$ & 0.48 & 0.65 \\
\hline & & & & & & $F_{1,14}=11^{b}$ & $<0.01$ & 0.43 & 0.85 \\
\hline & Peak "weak side" (N) & $1007 \pm 172$ & $991 \pm 173$ & $969 \pm 186$ & $943 \pm 181$ & $F_{3,12}=1.3^{c}$ & NS & & \\
\hline & Impulse "strong side" (N·s) & $361 \pm 66^{4}$ & $350 \pm 71$ & $343 \pm 77^{4}$ & $330 \pm 73$ & $F_{3,12}=21^{a}$ & $<0.001$ & 0.84 & 1.0 \\
\hline & & & & & & $F_{1,14}=3.7^{b}$ & NS & & 1.0 \\
\hline & Impulse "weak side" (N·s) & $420 \pm 73^{*}$ & $401 \pm 61^{*}$ & $368 \pm 57^{\star}$ & $328 \pm 55^{\star}$ & $F_{3,12}=27^{c}$ & $<0.001$ & 0.87 & \\
\hline & Propulsive impulse "strong side" $(\mathrm{N} \cdot \mathrm{s})$ & $41 \pm 7$ & $41 \pm 8$ & $41 \pm 8$ & $40 \pm 9$ & $F_{3,12}=5.2^{a}$ & $<0.05$ & 0.57 & 0.82 \\
\hline & Propulsive impulse "weak side" (N·s) & $41 \pm 8^{*}$ & $40 \pm 9$ & $38 \pm 7$ & $36 \pm 7$ & $\begin{array}{l}F_{1,14}=0.9^{D} \\
F_{3,12}=11^{c}\end{array}$ & $\begin{array}{c}\text { NS } \\
<0.001\end{array}$ & 0.74 & \\
\hline & Sideward impulse "strong side" (N·s) & $127 \pm 22^{4}$ & $126 \pm 23$ & $125 \pm 25^{4}$ & $119 \pm 25$ & $F_{3,12}=6.4^{a}$ & $<0.01$ & 0.62 & 0.89 \\
\hline & & & & & & $F_{1,14}=0.1^{b}$ & NS & & \\
\hline & Sideward impulse "weak side" (N·s) & $131 \pm 24^{3,4}$ & $128 \pm 21$ & $124 \pm 21$ & $118 \pm 21^{*}$ & $F_{3,12}=1.9^{c}$ & NS & & \\
\hline & Vertical impulse "strong side" (N·s) & $335 \pm 62$ & $324 \pm 67$ & $317 \pm 73$ & $304 \pm 68^{*}$ & $F_{3,12}=24^{a}$ & $<0.001$ & 0.86 & 1.0 \\
\hline & & & & & & $F_{1,14}=4.4^{b}$ & NS & & 1.0 \\
\hline & Vertical impulse "weak side" (N·s) & $395 \pm 69^{*}$ & $376 \pm 58^{*}$ & $342 \pm 53^{*}$ & $303 \pm 51^{*}$ & $F_{3,12}=28^{c}$ & $<0.001$ & 0.87 & \\
\hline
\end{tabular}

The values presented are means \pm SD. $F$ and $P$ values were obtained by two-way ANOVA $(4 \times 2$ : skiing speed $\times$ body side [strong vs weak]).

NS, not statistically significant.

*Statistically different from all other speeds.

${ }^{2}$ Statistically different from $14 \mathrm{~km} \cdot \mathrm{h}^{-1}$.

${ }^{3}$ Statistically different from $15 \mathrm{~km} \cdot \mathrm{h}^{-1}$

${ }^{4}$ Statistically different from $16 \mathrm{~km} \cdot \mathrm{h}^{-1}$.

${ }^{a}$ Main effect between skiing speeds.

${ }^{b}$ Main effect between body sides (strong vs weak side).

Interactive effect: skiing speed-body side.

and "strong" sides was negatively correlated to $V_{\text {peak }}(r=$ -0.52 to $r=-0.58$, all $P<0.05$ ) - the smaller the difference (i.e., the more synchronous), the better the performance. Total effectiveness demonstrated a positive association with $V_{\text {peak }}$ ( $r=0.53$ to $r=0.57$, all $P<0.05$ ) - the greater the effectiveness (i.e., ratio of propulsive to resultant force), the better the performance. The edging angle on the "weak side" during start of ground contact was negatively related to $V_{\text {peak }}$ at the speeds of $15 \mathrm{~km} \cdot \mathrm{h}^{-1}(r=-0.52, P<0.05)$ and $16 \mathrm{~km} \cdot \mathrm{h}^{-1}(r=-0.77, P<0.001)$ - the smaller or even negative edging angle, the better the peak performance. Cycle length, either absolute or normalized to body height, was not associated with $V_{\text {peak }}$ or the impulse of total propulsive forces within the same cycle. Only the resultant pole and plantar forces were correlated to propulsive forces, with no correlations of kinematic variables.

\section{DISCUSSION}

The present investigation revealed that: (a) in connection with the V1 skating technique, the upper- and lower-body contributed almost equally to propulsion (44\% and 56\%, respectively); (b) these relative contributions were independent of skiing speed; (c) whereas pole motion was asymmetric, motion by the legs on the "weak side" and "strong side" was highly symmetric with respect to the time course of the edging angle, the resultant force, and the force components calculated; (d) skiers with higher $V_{\text {peak }}$ demonstrated more well-synchronized pole motion, with more symmetric leg motion and greater effectiveness in transforming the resultant forces into propulsion; and (e) cycle length was not correlated with either peak velocity or the total propulsive force impulse.

For the determination of the force components associated with the skating techniques of XC skiing, systems of force plates alone or in combination with $3 \mathrm{D}$ kinematics can be used to assess the 3D orientation of the resultant forces. With insole pressure systems, the only interference comes from the measuring equipment located in the hip belt, allowing the skier to use standard skis and boots. Therefore, the external validity of this approach can be regarded as high.

Systems of force plates located on or under the track can be used effectively to monitor the classic techniques, where the skis are constrained to well-defined tracks. With an appropriate array of such plates, the resultant and component 


\begin{tabular}{|c|c|c|c|c|c|c|c|c|}
\hline \multirow[b]{2}{*}{ Parameter } & \multicolumn{4}{|c|}{ Speed $\left(\mathrm{km} \cdot \mathrm{h}^{-1}\right)$} & \multirow[b]{2}{*}{$F$} & \multirow[b]{2}{*}{$P$} & \multirow{2}{*}{$\begin{array}{c}\text { Effect } \\
\text { Size }_{p} \eta^{2}\end{array}$} & \multirow{2}{*}{$\begin{array}{c}\text { Test } \\
\text { Power }\end{array}$} \\
\hline & 13 & 14 & 15 & 16 & & & & \\
\hline Total impulse of forces $(\mathrm{N} \cdot \mathrm{s})$ & $877 \pm 126^{\star}$ & $845 \pm 115^{\star}$ & $799 \pm 111^{*}$ & $739 \pm 111^{*}$ & $F_{3,12}=25^{a}$ & $<0.001$ & 0.87 & 1.0 \\
\hline Propulsive total impulse of forces (N.S) & $145 \pm 17$ & $142 \pm 17$ & $136 \pm 15^{\star}$ & $129 \pm 16^{\star}$ & $F_{3,12}=22^{a}$ & $<0.001$ & 0.86 & 1.0 \\
\hline Average cycle force $(\mathrm{N})$ & $773 \pm 104$ & $780 \pm 107$ & $786 \pm 112$ & $785 \pm 122$ & $F_{3,12}=1.7^{a}$ & NS & & \\
\hline Average propulsive cycle force (N) & $127 \pm 15^{\star}$ & $131 \pm 16^{4}$ & $133 \pm 16$ & $138 \pm 18$ & $F_{3,12}=5.3^{a}$ & $<0.05$ & 0.59 & 0.80 \\
\hline Power output in the skiing direction (W) & $460 \pm 54^{\star}$ & $510 \pm 62^{*}$ & $556 \pm 67^{\star}$ & $613 \pm 78^{*}$ & $F_{3,12}=61^{a}$ & $<0.001$ & 0.94 & 1.0 \\
\hline$\%$ propulsion generated by the poles & $44 \pm 5$ & $44 \pm 6$ & $43 \pm 5$ & $42 \pm 5$ & $F_{3,12}=1.6^{a}$ & NS & & \\
\hline$\%$ vertical forces generated by the legs & $89 \pm 2$ & $89 \pm 2$ & $89 \pm 2$ & $89 \pm 2$ & $F_{3,12}=1.0^{a}$ & NS & & \\
\hline$\%$ sideward forces generated by the legs & $93 \pm 2$ & $93 \pm 2$ & $93 \pm 2$ & $93 \pm 2$ & $F_{3,12}=1.6^{a}$ & NS & & \\
\hline \multicolumn{9}{|l|}{ Effectiveness $^{d}$} \\
\hline \multirow[t]{2}{*}{ Poles (\%) } & $59 \pm 4^{4}$ & $59 \pm 4$ & $59 \pm 4$ & $60 \pm 4$ & $F_{3,12}=13^{a}$ & $<0.001$ & 0.75 & 1.0 \\
\hline & & & & & $F_{1,14}=185^{b}$ & $<0.001$ & 0.93 & 1.0 \\
\hline Legs $(\%)$ & $11 \pm 1^{3,4}$ & $11 \pm 1$ & $11 \pm 1$ & $12 \pm 1^{*}$ & $F_{3,12}=0.9^{c}$ & NS & & \\
\hline \multirow[t]{2}{*}{ "Strong side" pole (\%) } & $56 \pm 5$ & $56 \pm 5$ & $56 \pm 4$ & $58 \pm 4^{\star}$ & $F_{3,12}=6.2^{a}$ & $<0.01$ & 0.63 & 0.87 \\
\hline & & & & & $F_{1,14}=57^{b}$ & $<0.001$ & 0.81 & 1.0 \\
\hline "Weak side" pole (\%) & $64 \pm 3$ & $64 \pm 4$ & $65 \pm 4$ & $65 \pm 4$ & $F_{3,12}=2.0^{c}$ & NS & & \\
\hline "Strong side" leg (\%) & $11.5 \pm 0.9^{2}$ & $11.9 \pm 1.2$ & $12.0 \pm 0.9$ & $12.1 \pm 1.4$ & $F_{3,12}=12^{a}$ & $<0.001$ & 0.75 & 0.99 \\
\hline \multirow[t]{2}{*}{ "Weak side" leg (\%) } & $9.9 \pm 1.2$ & $9.9 \pm 1.5$ & $10.3 \pm 1.6$ & $11.2 \pm 1.9^{\star}$ & $F_{1,14}=6.8^{b}$ & $<0.05$ & 0.33 & 0.68 \\
\hline & & & & & $F_{3,12}=4.5^{c}$ & $<0.05$ & 0.53 & 0.75 \\
\hline Overall effectiveness (\%) & $16.6 \pm 0.8^{3,4}$ & $16.9 \pm 0.7$ & $17.1 \pm 0.8$ & $17.6 \pm 1.0^{\star}$ & $F_{3,12}=14^{a}$ & $<0.001$ & 0.79 & 1.0 \\
\hline
\end{tabular}

The values presented are means \pm SD.

NS, not statistically significant.

*Significantly different from all other speeds.

${ }^{2}$ Significantly different from $14 \mathrm{~km} \cdot \mathrm{h}^{-1}$.

${ }^{3}$ Significantly different from $15 \mathrm{~km} \cdot \mathrm{h}^{-1}$

${ }^{4}$ Significantly different from $16 \mathrm{~km} \cdot \mathrm{h}^{-1}$

${ }^{a}$ Main effect between skiing speeds.

${ }^{b}$ Main effect between body side (strong vs weak side).

${ }^{c}$ Interactive effect: skiing speed-body side.

${ }^{d}$ Effectiveness is calculated as the propulsive force component expressed as percentage of the resultant force. Fand $P$ values were obtained by two-way ANOVA (4 $\times 2$ : skiing speed $\times$ body side [strong vs weak]).

forces of each ski and pole can be measured independently $(14,15,40)$. However, such separate measurements are problematic, in the case of skating techniques, where the skis may be placed anywhere.

Furthermore, the motion involved in XC skiing is complex, consisting of simultaneous application of force at as many as four different points (two poles + two skis). The resulting partial overlap in measurements of the ground reaction forces of the legs and poles makes it difficult or even impossible to identify the individual forces. However, combination of pole force and insole systems with 3D motion capture (e.g., video or infrared systems) described here can be used effectively both in the laboratory and in the

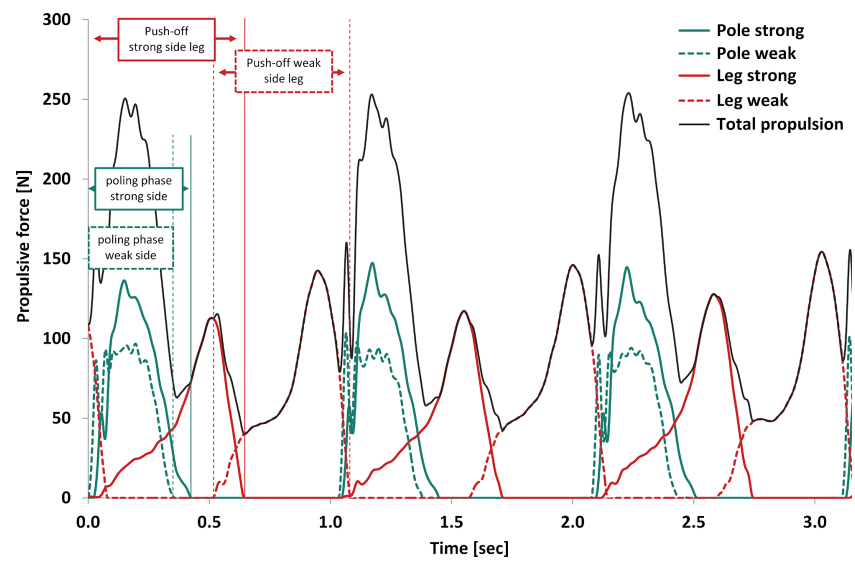

FIGURE 2-Time course of the force components in direction of skiing of both poles and legs and of the total force in direction of skiing (the sum of all four components) for one skier skating at $16 \mathrm{~km} \cdot \mathrm{h}^{-1}$. field. Although similar methods have been applied to ski skating previously (e.g., Smith et al. [30,32]), the speeds analyzed and the performance level of the skiers were lower than those in the current study, which involved world-class athletes skiing at a range of high submaximal speeds.

Comparison with other reports on the V1 technique. The cycle rate of $0.88-1.06 \mathrm{~Hz}$ and cycle length of $4.10-4.25 \mathrm{~m}$ observed here are quite similar to previous findings on the V1 technique, both on snow and using roller skis $(4,17,21,25,31,32,38)$. At the same time, the cycle rate here was approximately $18 \%$ lower than the $1.3 \mathrm{~Hz}$ recorded during maximal speed trials at an incline of $7^{\circ}-10^{\circ}$ on snow by Stöggl et al. (35). This difference might reflect differences between a maximal sprint trial of short duration and the longer incremental peak speed test $(\sim 68 \mathrm{~s})$ used here and/or the greater difficulty in attaining maximal cycle rates when roller skiing than when skiing on snow.

The angles of the skis with respect to the direction of skiing during ground contact we observed $\left(19^{\circ}\right.$ for the "strong side" and $17^{\circ}-18^{\circ}$ for the "weak side") are considerably narrower than those observed previously on snow $\left(25.3^{\circ}-28.5^{\circ}\right.$ for the "strong side" and $22.7^{\circ}-30^{\circ}$ for the "weak side") $(31,32)$ but comparable with those reported by Smith et al. (30) $\left(18^{\circ}-20^{\circ}\right)$. This difference might be due to the higher skiing speeds and/or different incline used here, differences between skiing on snow and roller skiing, changes in skiing equipment (e.g., more rigid poles and faster, stiffer, and more stable skis), the conditioning of the participating athletes (with greater upper-body capacity and involvement during XC skiing), and/or a change in the V1 
technique during the past few decades, with skiers now skating with a smaller "V" than in the 1980s.

The influence of speed. An important aspect of locomotion kinematics and kinetics is the mechanism(s) used to control velocity (18). Here, increasing speed was associated with an increase in cycle rate, whereas the cycle length was slightly longer at $14 \mathrm{~km} \cdot \mathrm{h}^{-1}$ than at $13 \mathrm{~km} \cdot \mathrm{h}^{-1}$ but remained constant thereafter up to $16 \mathrm{~km} \cdot \mathrm{h}^{-1}$, in agreement with previous findings, both on snow or with roller skis $(20,22)$. Positioning of the body during a cycle of V1 skating changed with increasing speed in several ways: (a) a greater edging angle on ground contact, especially for the "weak side" leg, whereas at the end of leg push-off, this angle rose more for the "strong side" leg; (b) a reduction in the forward covered distance of the poles at the time of pole plant, paralleled by a more inclined pole in forward direction; and (c) a larger forestep, particularly with the "strong side" leg, attributed also to the switch to a jumping V1 technique in some of the skiers. These changes might reflect the more rapid cycle rate, with less swing time for both the poles and legs, allowing less time overall to reposition the poles and roller skis for the next cycle.

Furthermore, with the exception of an elevation in peak pole forces, all other resultant and component peak forces and impulse of forces assessed were attenuated with increasing speed. The reduction in the ground contact time for both the legs and poles at higher speeds must be compensated for by a more rapid cycle rate, a body position that allows more rapid generation of propulsion (i.e., greater edging angle and more inclined pole angle in a forward direction leading to more pronounced propulsive force, although at the cost of shortening these phases) and a larger distance covered in each step through the use of a longer forestep (e.g., by jumping from the end of the "weak side" push-off to the next set down of the "strong side" leg). This finding is supported further by the enhancement in total effectiveness with increasing speed, demonstrating that a greater proportion of the resultant force applied is converted in propulsive force.

To our knowledge, only two other studies have analyzed components of propulsive force during skating at different speeds. Smith et al. (30) demonstrated that the ACPF increased with velocity, which was also partly the case here. The ACPF we observed was slightly larger than that reported by Smith et al. (30). However, in light of the balance of force, the ACPF should be constant, at least under laboratory conditions where there is no air resistance, in contrast to the outdoor measurements performed by Smith (26). One possible explanation for the increase in ACPF in the present investigation is that increased dynamics and enhanced side slipping of the roller skis at higher speeds elevated rolling resistance, a possibility that requires further examination.

Description of the V1 technique. Our current findings demonstrate certain pronounced differences in the pole and leg forces on the "strong" and "weak" sides of the body, highlighting the asymmetry of the V1 technique. The "strong side" pole generated more resultant and propulsive impulse of force (56-64 vs 33-43 N and 32-36 vs $22-28 \mathrm{~N}$, respectively). Although the "weak side" pole was more effective in transforming the resultant component into propulsive force $(64 \%-65 \%$ vs $56 \%-58 \%)$, the "strong side" pole provided more support in the vertical direction. Furthermore, the "weak side" pole contributed four times as much in the sideward direction (13-15 vs $4 \mathrm{~N}$ ). These observations can be attributed primarily to the asymmetric placement of the poles throughout the skating cycle, being more vertical on the "strong side" and more forward and sideward inclined on the "weak side." This difference also explains the earlier plant of the "weak side" pole, as well as the earlier lift-off of the pole at the end of the poling phase on this side, resulting in a total poling time that is shorter.

Regarding leg motion, there was an interaction effect indicating greater resultant and vertical impulse of forces for the "weak side" leg push-off at the slower speeds, with similar values for both sides at the higher skiing speeds, attributable primarily to a reduction in the push-off forces on the "weak side." The propulsive leg force impulse did not differ between the "strong" and "weak" sides, whereas an interaction effect leading to a decrease on the "weak side" was also seen. Overall, the leg push-off was more effective on the "strong side" than on the "weak side" (11\%-12\% vs $10 \%-11 \%)$, possibly because of the longer forestep and larger edging angle at the end of leg push-off observed for the "strong side" only, as well as the smaller reduction in ground contact time on the "strong side" with increasing speed. On both sides of the body, and especially on the "strong side," the skis were edged immediately after set-down. On the "strong side," the edging angle increased linearly with time, whereas on the "weak side" in some of the skiers (mostly the weaker ones), a slight increase in edging angle occurred during the first half of the ground contact phase. These observations demonstrate that leg work is less asymmetric than the movement of the poles.

Independent of speed, the poles contributed approximately $42 \%-44 \%$ to forward propulsion and were more effective than the legs $(59 \%-60 \%$ vs $11 \%-12 \%)$. Nonetheless, the legs contributed more overall to propulsion than the poles while also contributing to a great extent to the vertical and sideward motions of the skier.

Overall, the V1 skating technique demonstrated here an effectiveness of $17 \%-18 \%$, and this effectiveness was enhanced as the speed increased, in partial agreement with a study involving of four collegiate-level skiers using instrumented poles and roller skis on a $7^{\circ}$ uphill (38). This other report demonstrated that pole forces accounted for a large proportion of the total force involved in V1 skating ( $40 \%-50 \%$ of body weight), with most of the vertical and lateral forces being provided by the roller skis and with propulsive forces distributed rather evenly between the roller skis and poles. An increase in velocity was found to involve a larger increase in poling than leg forces. This latter finding was not confirmed here, which may again reflect differences between laboratory and field conditions (38).

In addition, Smith (26) reported that, with "citizen" racers, the pole forces contributed $66 \%$ of the propulsive force and 
less than $20 \%$ of the lateral and vertical forces. Skating forces were largest in the vertical and lateral directions and served primarily to promote lateral motion and support the body against gravity, contributing little to propelling the skier uphill. These findings contradict with our own and might reflect changes in V1 technique and skiing equipment over the past few decades and/or differences between world-class and "citizen" skiers as already stated above.

In association with the V1 technique, pole and leg work overlap, as do the push-offs by the "strong" and "weak" leg (with the exception of when jumping from a "weak side" push-off to "strong side" leg ground contact at higher skiing speeds). Therefore, application of force by the poles and legs is continuously interlocked, providing almost steady propulsive forces with no "dead" points where the skier is simply gliding. This relatively steady generation of propulsive forces may be the major advantage of using the V1 (rather than V2 or V2 alternate) technique on steeper slopes, where gravity will tend to slow the skier down substantially whenever propulsion is lacking. This consideration might explain why "diagonal skating" is preferred on very steep slopes (e.g., final climb at the Tour de Ski), the V1 technique on moderate and V2 on shallow slopes, and V2 alternate on flat terrain. However, this remains to be examined, for example, by analyzing the variability in propulsive force in association with the motion of the COM during a complete cycle using the various skating techniques.

In addition, the push-off of the "strong" leg is terminated after the pole work, leading to a short single-leg stance before the "weak side" ski touches the ground (see Fig. 2). It is worth noting that Clauß (8) recently emphasized the importance of a single stance during leg push-off for optimal performance (i.e., delay of the leg push-off with respect to pole work and/or later set-down of the "weak side" leg).

Correlations to $\boldsymbol{V}_{\text {peak. }}$. In the current investigation, only a few variables were associated with V1 performance (as reflected in $V_{\text {peak }}$ ). The faster skiers exhibited (a) a more closely synchronized pole work, with less time elapsing between the set-down of the "weak side" and "strong side" poles; (b) higher effectiveness in transforming resultant forces into propulsion, thereby "wasting" less force; and (c) a smaller edging angle for the "weak side" ski during ground contact, demonstrating their ability to set down the roller ski more directly under the COM, particularly at higher speeds. The more closely synchronized pole work is somewhat in contradiction with anecdotal beliefs that serial set-down of the poles provides steadier transformation of forces into propulsion during V1 skating.

In contrast to previous findings $(4,7,9,17,25,31,32)$, there was no correlation here between cycle length and performance. Furthermore, also in contrast to earlier reports (31), ski angles on the "weak side" and performance were not correlated. The absence of such correlations in this investigation might reflect the high level of performance of our participants, where the variation in any single biomechanical variable is smaller and where most already use a more-or-less optimal V1 skating technique with individual characteristics not related to performance.

Limitations. Pressure insoles measure only the vertical force component, without differentiating into lateral and horizontal forces. Therefore, the methods applied here might underestimate shared forces during the skating push-off. Recently, Ohtonen et al. (23) demonstrated that, during skate skiing, the mean difference in the vertical force component determined with Pedar insoles or a skate binding was approximately $13.0 \%$. However, as stated above, the mean absolute value provided by our system differed only by approximately $2.3 \%$ (plantar forces) from that provided by an AMTI force plate. Consequently, in the current study, components of leg force might be slightly underestimated.

Furthermore, in the leg push-off model applied here, determination of the edging angle was based on the position of the lower leg, but this does not necessarily result in a force vector that passes through the center of mass. However, a pilot study by Clauß (8) revealed that, indeed, during a skating push-off, the resultant force vector does not pass exactly through the center of mass. In addition, calculation of the center of mass is generally based on an anthropometric model that assumes that body segments behave rigidly and can be characterized well by parameters that can be estimated with only limited accuracy. We therefore decided to use a simpler model. However, future studies on these two topics are well warranted.

\section{CONCLUSIONS}

The present study provides new insights into the relative contributions of the upper and lower body of the "strong" and "weak" sides to propulsion during V1 skating. Furthermore, novel information about the basic coordination of arm and leg work during V1 skating at high skiing speeds and elite athletes is provided. Methodologically, the use of pressure insoles and 3D kinematics in combination with the leg push-off model, as described here, can easily be applied to all skating techniques, aiding in the evaluation and comparison of effectiveness. Such knowledge can help coaches and athletes to improve insufficient techniques, as well as to decide which technique should be used on any given terrain and to analyze the effects of unloading certain body parts and/or muscle groups during a race. Finally, the method proposed here could be used by the sporting industry to develop skiing equipment that enhances maximal force distribution, effectiveness, and performance.

The authors would like to express appreciation for the support of Ebru Cetin and Elif Öz during the data processing and Paolo Sereni for the mechanistic discussions about the presented push-off model. The authors also would like to express their gratitude to the participating athletes for their cooperation during the study, which was supported by the Swedish Olympic Committee.

No funding was received for this work. The authors declare no conflict of interest. None of the authors had any professional relationships with companies or manufacturers who will benefit from the results of the present study.

Reporting of these findings does not constitute endorsement by the American College of Sports Medicine. 


\section{REFERENCES}

1. Ainegren M, Carlsson P, Tinnsten M. Rolling resistance for treadmill roller skiing. Sports Eng. 2008;11:23-9.

2. Andersson E, Supej M, Sandbakk O, Sperlich B, Stöggl T, Holmberg HC. Analysis of sprint cross-country skiing using a differential global navigation satellite system. Eur J Appl Physiol. 2010;110(3):585-95.

3. Babiel S, Neumaier A. Messmethode zur Erfassung der vortriebswirksamen Kräfte beim Skilanglauf [Measurement methods for determination of propulsive forces in cross-country skiing]. In: Wiemeyer J, editor. Forschungsmethodologische Aspekte von Bewegung, Motorik und Training im Sport, Schriften der Deutschen Vereinigung für Sportwissenschaft [Researchmethodological aspects of motion, motor control and training in sports, Abstracts of the German association of sport science]. Hamburg: Czwalina Verlag; 1999. pp. 196-200.

4. Bilodeau B, Boulay MR, Roy B. Propulsive and gliding phases in four cross-country skiing techniques. Med Sci Sports Exerc. 1992; 24(8):917-25.

5. Bilodeau B, Roy B, Boulay MR. A comparison of three skating techniques and the diagonal stride on heart rate responses and speed in cross-country skiing. Int J Sports Med. 1991;12(1):71-6.

6. Bilodeau B, Rundell KW, Roy B, Boulay MR. Kinematics of crosscountry ski racing. Med Sci Sports Exerc. 1996;28(1):128-38.

7. Boulay MR, Rundell KW, King DL. Effect of slope variation and skating technique on velocity in cross-country skiing. Med Sci Sports Exerc. 1995;27(2):281-7.

8. Clauß M. Biomechanische Explikationen zu den SkatingSkilanglauftechniken [Biomechanical explications of the skating cross-country skiing techniques]. Leipzig (Germany): Universität Leipzig, Sportwissenschafltiche Fakultät; 2011.

9. Dillman C, Schierman G. Biomechanical Features of Uphill "Ski Skating," on Cross-country Skis. Colorado Springs (CO): Biomechanics Laboratory, United States Olympic Commitee; 1986.

10. International Ski Federation (FIS), editor. The International Ski Competition Rules (ICR). Book II, Cross-country. Oberhofen (Switzerland): Internatinal Ski Federation FIS; 2013. p. 85.

11. Gregory RW, Humphreys SE, Street GM. Kinematic analysis of skating technique of olympic skiers in the women's $30-\mathrm{km}$ race. $J$ Appl Biomech. 1994;10(4):382-92.

12. Hoffman MD, Clifford PS, Bender F. Effect of velocity on cycle rate and length for three roller skiing techniques. J Appl Biomech. 1995;11:257-66.

13. Holmberg HC, Lindinger SJ, Stöggl TL, Eitzlmair E, Müller E. Biomechanical analysis of double poling in elite cross-country skiers. Med Sci Sports Exerc. 2005;37(5):807-18.

14. Komi PV. Ground reaction forces in cross-country skiing. In: Winter DA, editor. Biomechanics $I X-B$. Champaign (IL): Human Kinetics; 1985. pp. 185-90.

15. Komi PV. Force measurements during cross-country skiing. Int $J$ Sport Biomech. 1987;3(4):370-81.

16. Kvamme B, Jakobsen V, Hetland S, Smith G. Ski skating technique and physiological responses across slopes and speeds. Eur $J$ Appl Physiol. 2005;95(2-3):205-12.

17. Lee D-W, Kwak C-S, Kwon Y-H, Choi G-C. Analysis of V1 skating technique in Korean cross-country skiers. Kor J Sport Sci. 1997;9:58-74.

18. Lindinger SJ, Stöggl T, Müller E, Holmberg H-C. Control of speed during the double poling technique performed by elite crosscountry skiers. Med Sci Sports Exerc. 2009;41(1):210-20.

19. Losnegard T, Myklebust H, Hallen J. No differences in $\mathrm{O}_{2}$-cost between $\mathrm{V} 1$ and $\mathrm{V} 2$ skating techniques during treadmill roller skiing at moderate to steep inclines. J Strength Cond Res. 2012;26(5):1340-7.

20. Millet GY, Hoffman MD, Candau RB, Clifford PS. Poling forces during roller skiing: effects of grade. Med Sci Sports Exerc. 1998; 30(11):1637-44.
21. Myklebust H, Losnegard T, Hallen J. Differences in V1 and V2 ski skating techniques described by accelerometers. Scand J Med Sci Sports. 2013:Epub 1-12.

22. Nilsson J, Tveit P, Eikrehagen O. Effects of speed on temporal patterns in classical style and freestyle cross-country skiing. Sports Biomech. 2004;3(1):85-107.

23. Ohtonen $\mathrm{O}$, Lindinger S, Lemmettylä T, Seppälä S, Linnamo V. Validation of portable 2D force binding systems for cross-country skiing. Sports Eng. 2013;16(4):281-96.

24. Ohtonen O, Lindinger S, Linnamo V. Effects of gliding properties of cross-country skis on the force production during skating technique in elite cross-country skiers. Int J Sports Sci Coach. 2013;8(2): 407-16.

25. Rundell KW, McCarthy JR. Effect of kinematic variables on performance in women during a cross-country ski race. Med Sci Sports Exerc. 1996;28(11):1413-7.

26. Smith GA. The effect of velocity and grade on the kinematics and kinetics of V1 skating in cross-country skiing [doctoral dissertation]. University Park (PA): The Pennsylvania State University; 1989. p. 169.

27. Smith GA. Biomechanical analysis of cross-country skiing techniques. Med Sci Sports Exerc. 1992;24(9):1015-22.

28. Smith GA. Cross-country skiing: Technique, equipment and environmental factors affecting performance. In: Zatsiorsky V, editor. Biomechanics in Sport. IOC Encyclopedia of Sports Medicine Series. Oxford (UK): Blackwell Science; 2000. pp. 247-70.

29. Smith GA, Heagy BS. Kinematic analysis of skating technique of olympic skiers in the men's 50-km race. J Appl Biomech. 1994;10(1):79-88.

30. Smith GA, Kvamme B, Jakobsen V. Effectiveness of ski and pole forces in ski skating. In: Müller E, Lindinger S, Stöggl T, editors. Science and Skiing IV. Maidenhead (UK): Meyer \& Meyer Sport; 2009. pp. 647-56

31. Smith GA, Mc Nitt-Gray J, Nelson RC. Kinematic analysis of alternate stride skating in cross-country skiing. Int J Sport Biomech. 1988;4(1):49-58.

32. Smith GA, Nelson RC, Feldman A, Rankinen JL. Analysis of V1skating technique of Olympic cross-country skiers. Int $J$ Sport Biomech. 1989;5(2):185-207.

33. Stöggl T, Hébert-Losier K, Holmberg HC. Do anthropometrics, biomechanics, and laterality explain V1 side preference in skiers? Med Sci Sports Exerc. 2013;45(8):1569-76.

34. Stöggl T, Holmberg HC. Force interaction and 3D pole movement in double poling. Scand J Med Sci Sports. 2011;21(6): e393-404.

35. Stöggl T, Kampel W, Müller E, Lindinger S. Double-push skating versus V2 and V1 skating on uphill terrain in cross-country skiing. Med Sci Sports Exerc. 2010;42(1):187-96.

36. Stöggl T, Lindinger S, Müller E. Analysis of a simulated sprint competition in classical cross country skiing. Scand J Med Sci Sports. 2007;17(4):362-72.

37. Stöggl T, Müller E, Lindinger S. Biomechanical comparison of the double-push technique and the conventional skate skiing technique in cross-country sprint skiing. J Sports Sci. 2008;26(11):1225-33.

38. Street GM. Kinetic analysis of the V1 skating technique during roller skiing [dissertation]. University Park (PA): The Pennsylvania State University; 1988. p. 128.

39. Street GM, Frederick EC. Measurement of skier-generated forces during roller-ski skating. J Appl Biomech. 1995;11(3):245-56.

40. Vähäsöyrinki P, Komi PV, Seppala S, Ishikawa M, Kolehmainen V, Salmi JA, Linnamo V. Effect of skiing speed on ski and pole forces in cross-country skiing. Med Sci Sports Exerc. 2008;40(6):1111-6.

41. Wenger U, Vogel A, Geiger L. Optimale Skilanglauf-Technik 2, Freie Technik-Skating [Optimal cross-country skiing technique 2, freestlyle technique]. Oberhaching: sportinform Verlag; 1988. 176 p. 